\title{
(YOU GOTTA HAVE) FRIENDS: CARE LEAVING, FRIENDSHIPS, AND AGENCY INTERVENTION
}

\section{Varda R. Mann-Feder}

\begin{abstract}
This article is based on a presentation at FICE Austria in 2016 that reported on the findings of a qualitative study that explored the perceptions of friendships held by young people in and formerly in care. Eleven young people from the care system and three frontline child and youth care workers were interviewed with a focus on the effects of out-of-home placement on the development of peer relationships. Results suggest that there are significant obstacles to the development of age-appropriate friendships both within the care system and between youth in care and their community peers. These findings are discussed in light of the evidence that friendships are critical for healthy development and can serve as a buffer against stigma for youth who have been placed in out-of-home care. The study reported here is part of a larger program of research, the goal of which is to identify protective mechanisms or developmental assets in the transition to adulthood that could be better cultivated for youth aging out of placement.
\end{abstract}

Keywords: youth in care, friendship, developmental assets

Acknowledgement: This study was funded by a grant from The Centre for Human Relations and Community Studies at Concordia University. The author wishes to acknowledge the invaluable contributions of Riham Ahmed.

Varda R. Mann-Feder PhD is a Professor in the Department of Applied Human Sciences, Concordia University, 7141 Sherbrooke Street West, Room VE 227-3, Montreal H4B 1R6, Canada. Email: varda.mann-feder@concordia.ca 
International Journal of Child, Youth and Family Studies (2018) 9(1): 154-167

The critical importance of friendships in development is among the best documented and most robust findings in developmental psychology (Lerner \& Steinberg, 2009). Normative peer relationships, especially in adolescence and emerging adulthood, teach relevant skills not learned elsewhere and support development in multiple domains, such as self-esteem, selfdifferentiation, a sense of agency, and the capacity for healthy autonomy (Snow \& Mann-Feder, 2013). Once most young people enter high school, they spend twice as much time with peers as with their families; from then on, activities with friends occupy more time than any other activities except school (Coleman, 2011).

Having friends has also been identified as a critical source of resilience for youth in outof-home placement. Legault, Anawati, and Flynn (2006) developed a predictive model of adjustment for youth in care, based on data from 220 youth placed in Ontario. They found that having close friendships predicted lower levels of anxiety, less risk of aggression, and less frequent use of avoidant coping among youth in foster care. They concluded that "positive friendships may contribute to buffer or diminish the effects of cumulative risks on outcomes" (Legault et al., p. 1026). In an earlier study, Flynn, Robitaille, \& Ghazal (2006) found that selfrated perceptions of the quality of friendships among youth in care predicted placement satisfaction.

At the same time, it has been suggested that being in care in and of itself can create obstacles to the development of friendships (Office for Standards in Education, Children's Services and Skills, 2014). Moreover, multiple moves and changes of school may result in considerable instability, disrupting friendships. Rutman and Hubberstay (2016) interviewed youth formerly in care who ranged in age from 19 to 26 . Only $56 \%$ of their participants reported regularly turning to friends, although they were seen as a potential source of emotional support. This was in stark contrast to findings for their normative peers in the community, most of whom turned to friends for support on a range of important personal issues (Arnett, 2013). Emond (2014) interviewed 14 youth aged 8 to 18 in residential homes in Ireland and found that relationships with peers at school could serve as a source of belonging and connection but could also elicit a sense of shame about being in care. She concluded that young people in care are left to manage their friendships on their own and have to reconcile their care status with social norms that dictate that growing up at home is optimal. This can influence both their capacity to make friends and their sense of self.

Some scholars have highlighted the special significance of friendships for youth aging out of care. Hiles, Moss, Wright, and Dallos (2013) undertook a systematic review of the international research on care leaving conducted between 2001 and 2013, and found a number of studies that cited friends as a source of emotional support and an entrée into the family lives of others. Smith (2011) advocated for a relationship-based approach for youth leaving care, stating that "youth need and benefit from relationships and the sharing of experiences with other youth who have been in foster care" (p. 228). Snow, H., and S. (2014) documented the value of peer support and peer mentoring for youth who have left care, and cited friendships as fostering 
International Journal of Child, Youth and Family Studies (2018) 9(1): 154-167

feelings of belonging and reducing isolation. Rogers (2017) recently identified friends as critical for helping young people from foster care manage "stigmatized care identity".

An earlier study by Mann-Feder, Eades, Sobel, and DeStefano (2014) compared the experiences of home leavers to those of care leavers. While moving out was described as a crisis by both home leavers and those leaving placement, the majority of youth in the community who had moved out on their own reported that they had benefited from some family support, both in the moving process itself and through the provision of a financial safety net. However, at the same time, youth leaving home reported that their friends had a critical role in their moving out process, by determining when they moved out, where they moved to, and how they adjusted after the move. Home leavers overwhelmingly reported that when they faced challenges after moving, they preferred to turn to friends for support rather than to their parents. This was especially true of the home leavers who had difficult relationships with their parents, and is consistent with literature that has suggested that peer acceptance and support can compensate for the effects of family adversity (Criss, Pettit, Bates, Dodge, \& Lapp, 2002).

Care leavers, on the other hand, did not identify either family or friends as particularly supportive; rather, they stressed the need to become independent and self-reliant. While home leavers mentioned spending time freely with friends as a significant benefit of leaving home, care leavers did not identify peer interactions as something to look forward to. As part of an earlier study, care leavers reported that they were actually coached by staff to avoid other youth who have left care, as they might potentially be taken advantage of (Mann-Feder \& White, 2003). Taken together, these findings are of particular concern: while the lack of family support is something that placement agencies can never compensate for, friendships constitute an important protective mechanism, especially in the transition to adulthood. Peer-centred strategies are urgently needed in child welfare, especially to assist youth in cultivating a peer support network that can persist beyond their departure from care (Snow \& Mann-Feder, 2013).

This article reports the findings of a qualitative study that further explored the role of friendships for youth in placement, as seen through the eyes of youth in care, youth who had left care, and experienced staff from the care system. An additional goal of this study was to question participants about their views on the feasibility of interventions designed to cultivate peer relationships through peer-managed groups and peer mentoring.

\section{Method}

Eleven youths and three staff from the child welfare systems in Montreal and Toronto were recruited for interviews. The study design was vetted by a university ethics committee and all participants were engaged in an informed consent process. The youths in this study ranged in age from 16 to 20, and had spent between 2 and 14 years in care. Two of the participants were female; one had left care and one was still in care. Two focus groups were conducted, one with four youths currently in care, and one with four youths who had left care. Three additional care 
International Journal of Child, Youth and Family Studies (2018) 9(1): 154-167

leavers were interviewed individually. Three staff who worked in a transition program for care leavers, two women and one man, were individually interviewed. The staff had considerable (up to 25 years) experience working with care leavers.

All interviews were conducted by two trained graduate students using a semi-structured interview guide. Participants were invited to share a meal with the interviewers and were paid an honorarium. Questions with all participants focused on friendship experiences while in care, the role of friendships in the lives of care leavers, and the identification of any organizational factors that may have influenced how friendships developed for young people in placement. Additionally, all participants were asked whether they thought that programs of peer mentoring and peer support could be helpful for youth exiting care.

All interviews were audiotaped and transcribed. A team of two - a third trained graduate student and the author - conducted the data analysis using a consensual qualitative research (CQR) approach (Hill, Thompson, \& Williams, 1997). CQR utilizes a team approach to analyzing themes and subthemes in the data, where all coding is worked out through discussion and only those findings that are agreed upon are retained. CQR also identifies themes in the data as general (shared by virtually all participants), typical (shared by the majority), or variant (unusual). Results for youth overall and results for staff overall were analyzed as two separate groups, and then compared.

\section{Results}

What follows is a description of general, typical, and variant themes for youth and for staff, with characteristic quotes in each area.

\section{Youth Participants}

Analysis of the interview transcripts yielded four major themes. There was a high level of unanimity among the 11 youth participants; the youth who had left care were in strong agreement with the youth currently in care. One major difference between the two groups, however, was in the tone of the responses. Those who had already left care tended to be serious, thoughtful, and reflective, while the focus group with the youth in care was more boisterous and emotional. It may be that this reflects the relative age and maturity of the youth who have left care, as well as their aged-out status and relative distance from issues they experienced while in care; at the same time, the youth in care may have experienced some anxiety in relation to the discussion.

The four generally supported themes identified by the youth participants were: friendships in care can be problematic; friends from care share a special bond; friendships with youth in the community are difficult, if not impossible, to maintain; and agency policy and staff interventions interfere with the formation of friendships. There was also a generally held view that peer-centred programs would be difficult to implement. 
International Journal of Child, Youth and Family Studies (2018) 9(1): 154-167

Friendships in care can be problematic: A view generally held by the youth in this study was that friendships between youth in care can be difficult. Some participants characterized friendships as transitory and hard to maintain: "You'll have a bunch of friends that you live with and a lot of them will start getting discharged", and, "It's like friends have an expiration date".

Another general perception was that friendships between youth in placement are not trustworthy and that youth in care take advantage of their friends. For example, participants stated:

They are the kind of friends that would steal from you when you have your wallet open.

Even if they're your friends, you cannot trust them.... Personally, I don't think you can trust anyone in care. Not because they are in care, but it's just that someone could be showing off as your friend and it does not mean anything.

Friends in care were also seen as a bad influence. As one participant reported, "I've had incidents where I interacted with the wrong people. And I got into trouble.... It ruined my reputation."

Friendships in care are close: At the same time, both youth in care and youth who had left care generally regarded their peers in placement as the only friends they could really trust. Participants stressed the importance of their shared experience, as demonstrated by these statements:

You're all living together. You know what that person feels. Though it may be a different situation, you know how it feels to have somebody tell you "No."

They feel your pain ... because they are in care.

A typical or majority view was that the shared experience creates a special bond. As the youth participants reported:

I still talk to a few people from group homes, and I don't know, it is just easier to be myself.

It's like family actually. You could wrestle and you would fight with somebody you live with, but you wouldn't do it to hurt them. We try to find things to do together, because we live together.

They already know everything, like, so I can't surprise them.

It is difficult to make friends from the community: The view that youth in care are easy to relate to contrasted with a general perception that making friends from outside the care 
system was extremely difficult. All the youth participants in this study shared the belief that the stigma they experienced as youth in care interfered with their capacity to make friends in the community. Here are examples of how the youth explained this:

They find out that you're not at home and they're, like, how come you don't live at home? And you don't want to answer that question. So it's easier not to even be in a situation where you are faced with that question.

I remember when my brother was in lockup, and all my friends, like, "Oh I heard your brother went to jail". I was, like, "Oh seriously?" So the first thing that went through my mind was that, whenever someone brings up where I live, I say the word "group home".

The majority of youth participants stressed that rules in their care environments also made it difficult to cultivate relationships with peers in the community. As they reported:

I was never really able to keep up with my friends from the outside world because I wasn't allowed to invite anybody back to my group home. Or I wasn't really allowed to go out.

You couldn't have time to hang out. So like, 15 minutes before and after school.

My friends in high school ... that's another reason why I couldn't keep them, just because they would ask for sleepovers or like prom. I couldn't stay out. They all wanted to go take their limo and go partying. I couldn't do any of that.

A small number of participants also pointed out that they had relatively limited access to digital technology and social media, and that this, too, impeded their ability to connect with community peers.

Staff intervention sometimes blocks friendships: Youth typically reported that staff intervened in their friendships in the care system, for fear that one young person would be influenced by the negative behaviors of others. As these participants stated:

I find they don't want people ... anyone ... to get too close to each other. They think we are doing criminal things.

The reason why we fought and stopped talking was because the group home didn't want us to be friends any more.... One time we didn't come back for hours $\ldots$ and they told us that if we were ever together again, we would switch group homes and that was it.

If we are out too long together, they would always get suspicious. "Oh, what are they up to?" And it was always bad, automatically bad. 
International Journal of Child, Youth and Family Studies (2018) 9(1): 154-167

One variant finding was that the female youth who participated in this study indicated that, for girls, gender issues resulted in even greater restrictions on friendships within and outside care. As the youth stated:

They think you are recruiting or escorting or you are doing God knows what.

Being with girls, it's a lot different. If I am friends with a girl who's been on the street, they'll automatically think I'm being manipulated onto the streets, even though I am just being a friend.

If I was to date people out of the system, it is a lot more difficult. My social worker would have to do background checks and that is disgusting.

Peer-centred programming would be difficult to implement: Lastly, when asked about the appeal and feasibility of peer mentoring and peer-managed groups, the youth participants stressed the complexities of mounting a program of this kind. They wondered if youth formerly in care could help anyone else, and stressed that any such initiative should be clearly dissociated from agency programs in order to succeed. Some characteristic suggestions were:

I wouldn't because I haven't stabilized myself. I am kind of struggling. So I can't help myself properly yet.... I don't think I'd be able to help someone else.

It would have to be serious and really well organized ... because it could turn into something else.

If you can make a group like that, then maybe far away from the system. So maybe have it run by somebody who is, was, in care, but left a few years ago, so is stable. Not run by anyone who is associated with a care worker, a social worker, whatever, or like a support worker.

\section{Staff Participants}

Analysis of the interviews with staff yielded three major themes: friendships in care can be problematic, friendships in care can be positive, and staff have a major role to play in how friendships evolve for youth in care. While staff endorsed the value of peer-centred practices, they expressed doubts about the feasibility of peer mentoring and peer-led groups.

Friendships in care can be problematic: A generally held view among staff participants was that the cause of negative relationships between youth in care is that peers negatively influence each other or that peers misuse or manipulate each other. As stated in the interviews:

I've seen that friendships tend to be negative, and they get each other in trouble. So it's a negative influence as opposed to "Hey, let's get together and help each other out" kind of thing. 
International Journal of Child, Youth and Family Studies (2018) 9(1): 154-167

I've seen kids who moved out on their own and thought that they were good friends with someone, and then realized that they were being used by that person who's still in the system. I had a girl who said they would come and "eat all your food".

The ones that develop, don't last. There's things like, "We were best friends today, but she stole from me."

A typical statement was that youth who are in care lack social skills and are therefore more likely to have difficult friendships:

A lot of the kids we have in care lack social skills and so it is difficult for them to make friends.

What I've observed is that some of them come in and with all their baggage and they're so damaged that they ... I don't want to say that they don't have the ability ... but it's like, "If I am friends with you in group homes it's because you have something that I need." It's that type of relationship.

Friendships in care can be positive: Despite this, two of the three staff stressed that having friends is important, and that friendships in care have special properties:

I see personally that it is much better to have friends, no matter bad or good, than to be isolated and feel alone.

I think they have a tendency to share with each other and that creates a bond. And that bond can be helpful later.

Close relationships with other youth in care were described generally by staff as particularly helpful to youth leaving care:

If you and I are close in age, I think the friendships are more maintained. Especially if we are both going to independent living, for example. There's something we have in common between us and I understand what you're going through.

It's interesting that a lot of the clients have left us, even if they didn't know each other in care, sometimes they tend to connect. Some are very supportive, helpful. There are some that have had really bad times, so they're able to say to someone, who's behind, "Okay, you need to practice your budgeting."

More and more now, our kids stay in touch with each other, and they could be helpful to each other. 
International Journal of Child, Youth and Family Studies (2018) 9(1): 154-167

A typical comment by staff participants was that youth who are in care have difficulty establishing positive contacts with peers in the community. As one reported:

I would say that for some of them, they feel intimidated coming out of the system and having that label. I have a girl now who's doing hairdressing but she feels she has nothing in common with the girls in her program... She feels on the inside that she has nothing in common with these kids or she's not equal to them.

Staff interventions influence friendships: All three staff acknowledged that care professionals have a role in influencing relationships both within the care system and between youth in care and youth in the community. However, they saw their role as both encouraging positive friendships and discouraging negative ones:

If we see that someone may have a positive influence on somebody, then yeah it would be encouraged. If it's a negative influence, then it will be discouraged.

I know if somebody is involved in a community activity that's positive, we may try to encourage, you know, some other kids to tag along. On the flipside of that, if Johnny's habit is to go hang out with his friends and get stoned ... [if] the other kids goes and does that, well, it will be clear that, "Sorry you can't go out with Johnny because last time the two of you went out together and you both came back stoned."

You know when it's not a good relationship or you know that the new kid is coming in and you have the kid who's always using people. Now you try to discourage it because you know that the new kid is vulnerable.

While staff saw their interventions as essentially protective in nature, there was an admission by one staff participant that these interventions might have a negative effect:

I don't want to say we're at fault, but if you take a kid in group home ... sometimes we have to call and make sure you're at Mary's house, because we don't have that trust or whatever. It sort of already makes you different because now the group home is calling Mary's mom.

Peer-centred programming would be difficult to implement: Lastly, when asked directly about the advisability of former youth in care mentoring youth who were getting ready to leave, all three staff expressed some support but also had reservations. The following are characteristic of their responses:

I like the idea ... but I would want to be selective about who would do the grouping. Because again, you might have the one that's going to school and doing what she needs to do when one was found with a whole bunch of drugs in her 
International Journal of Child, Youth and Family Studies (2018) 9(1): 154-167

apartment. You would want the one in school to be a good role model and try to help one to not do that, but I wouldn't want that one getting pulled back.

There are cases where attempts are made, but it's not easy. And they often times will burn each other, you know? I've seen friends move in together and be enemies in a short period of time.

While you may listen a bit more attentively, the general attitude of a 16-, 17-, 18-year-old remains, "Yeah, yeah, sure I know about it". Whether it comes from a father, a mother, a 50-year-old gran, even a 21-year-old peer that's been through it. In general, they may be more attentive with the 21-year-old, but it still remains, the attitude is more, "Yeah, yeah, I know."

It actually takes time to mentor kids. And you're asking these kids to be responsible, sometimes for school work, your apartment, and then you have your friendships. And then you're going to be asked to mentor someone else. It's asking a lot.

\section{Discussion and Conclusion}

Although the small sample size dictates cautious interpretation of these results, there was considerable alignment in this study among the views held by the three groups - youth in care, youth who have left care, and agency staff - about friendships among young people in placement. The high level of agreement also held up between youth in Montreal, and youth in Toronto, two distinct jurisdictions with different legislation and different care systems. The responses of the participants overall communicated the complexities and difficulties that youth placed away from home experience in making friends, both with other youth in care and their peers in the community.

Friendships in care, while highly valued for their level of familiarity and mutual identification, were described as difficult to maintain and fraught with trust issues. All the participants in this study had a strong belief in the possibilities for negative peer influence among youth in care, despite the lack of evidence for the existence of contagion as an objective feature of peer relationships (Snow \& Mann-Feder, 2013). This belief in contagion was evident in the views of both youth and staff on the feasibility of peer-led interventions and peer mentoring in the care system; all doubted that youth who had left care were stable enough or trustworthy enough to be of any help to other young people who are aging out.

Participants also expressed the shared view that staff serve as mediators of the friendships of young people in care, whether by discouraging contact, enacting rules, or enforcing resource limitations that make interacting with other young people difficult. Certainly, one of the staff interviewed for this study was acutely aware that in enforcing some agency rules, she was also 
creating problems that could interfere with the maintenance of friendships. Risk-averse practices run the risk of overprotecting youth in care to the point where relationships suffer.

While the youth in this study did not reflect on the potential for staff to make positive contributions to their friendships, staff reported that they did encourage positive interactions when they could. This echoes the work of Emond (2014), who stressed that adults need to actively help youth in care to make friends with "support and training ... to counter what have been difficult past relationship experiences" (p. 201), even though this is rarely considered an explicit responsibility of staff. While the staff in this study expressed concern that youth in care lack social skills and therefore struggle to make friends, there are indications that both active staff support and practice with peers are critical for overcoming this limitation. The Children's Society (2015), a charitable organization in England that supports youth in care, recently produced a guide to help promote friendships for children in placement. This document instructs adults on different strategies for helping youth in care, based on the premise that no opportunity should "be missed for children in care to have a friend" (The Children's Society, 2015, p. 5). The Society goes on to advocate that friendships should be considered so important that they become a part of all processes, procedures, and forms used on behalf of youth in placement (The Children's Society, 2015).

A striking finding of this study is the degree to which the experience of stigma was seen as interfering with opportunities for youth in care to connect with their community peers. This is wholly consistent with other research that has identified stigma as a major concern for youth who are or have been in care (Rogers, 2017; Snow, 2006; Snow, H., \& S., 2014). Not only is this one of the most painful sequelae of a history of being placed, the ripple effects created by stigma rob young people of access to experiences that might otherwise help to offset the deprivations of a care career. Friendships with youth outside the system have rich possibilities for positive modelling, inclusion in family life, and the opportunity to practice social skills and prosocial forms of leisure. At the same time, it has been well documented that one of the most powerful strategies for managing stigma for individual youth who are or have been in care is engagement in friendship networks with other youth who have experienced placement (Rogers, 2017). Promoting friendships for youth in care is thus both a developmentally informed intervention and a tool for combatting the stigmatizing effects of being in care. The benefits of supporting friendships among youth in care also extend to care leavers and alumni of care, where peer support can dramatically enhance the development of resilience (Snow et al., 2014). This has, in part, fueled what is now a worldwide movement to create self-governing networks for former youth from the care system. For examples, see Youth in Care Canada (http://youthincare.ca); Clan in Australia (http://www.clan.org.au); and Voices for Choices and Care Leavers Group (https://www.newcastle.gov.uk/health-and-social-care) in the United Kingdom.

While the participants in this study did not wholly endorse peer-managed groups and peer mentoring as feasible interventions for youth in care, their comments underscored the critical importance of friendships for youth who are or have been in care. Perhaps as a first step in peer- 
centred practice, efforts should be made to endorse friendships whenever possible and actively intervene with young people to help them better engage in peer relationships. Friendships, both in and outside the care system, should be actively advanced by adults whenever possible, and myths related to the contagion effect need to be openly discussed and reevaluated (Snow \& Mann-Feder, 2013). Practitioners, researchers, and policy makers need to examine how both values and actions can serve to facilitate or block access to friends. In a recent survey of foster parents and social workers in England, Scotland, Wales, and Northern Ireland, a participant stated, "If we don't address friendship opportunities for looked after young people and children, then we are adding to their social exclusion and failing in our duty as corporate parents" (The Children's Society, 2016, p. 9). 
International Journal of Child, Youth and Family Studies (2018) 9(1): 154-167

\section{References}

Arnett, J. (2013). Adolescence and emerging adulthood (5th ed.). New York, NY: Pearson.

Coleman, J. (2011). The nature of adolescence (4th ed.). New York, NY: Routledge.

Criss, M. M., Pettit, G. S., Bates, J. E., Dodge, K. A., \& Lapp, A. L. (2002). Family adversity, positive peer relationships, and children's externalizing behavior: A longitudinal perspective on risk and resilience. Child Development, 73, 1220-1237. doi:10.1111/1467$\underline{8624.00468}$

Emond, R. (2014). Longing to belong: Children in residential care and their experiences of peer relationships at school and in the children's home. Child \& Family Social Work, 19, 194202. doi:10.1111/j.1365-2206.2012.00893.x

Flynn, R., Robitaille, A., \& Ghazal, H. (2006). Placement satisfaction of young people living in foster homes. In R. Flynn, P. Dudding, \& J. Barber (Eds.), Promoting resilience in child welfare (pp. 191-265). Ottawa, ON: University of Ottawa Press.

Hiles, D., Moss, D., Wright, J., \& Dallos, R. (2013). Young people's experience of social support during the process of leaving care: A review of the literature. Children and Youth Services Review, 35, 2059-2071. doi:10.1016/j.childyouth.2013.10.008

Hill, C. E., Thompson, B. J., \& Williams, E. N. (1997). A guide to conducting consensual qualitative research. The Counselling Psychologist, 25, 517-572. doi:10.1177/0011000097254001

Legault, L., Anawati, M., \& Flynn, R. (2006). Factors favouring psychological resilience among fostered young people. Children and Youth Services Review, 28, 1024-1038. doi:10.1016/j.childyouth.2005.10.006

Lerner, R. M, \& Steinberg, L. (2004). The scientific study of adolescent development: Past, present, and future. In R. M. Lerner \& L. Steinberg (Eds.), Handbook of adolescent psychology (2nd ed., pp. 1-12). Hoboken, NJ: Wiley.

Mann-Feder, V. R., Eades, A., Sobel, E., \& DeStefano, J. (2014). Leaving home: A qualitative study. Canadian Journal of Family and Youth, 6(1). Retrieved from http://ejournals.library.ualberta.ca/index/php/cjfy

Mann-Feder, V., \& White, T. (2003) The transition to independent living: Preliminary findings from the experiences of youth in care. In K. Kufeldt \& B. McKenzie (Eds.), Child welfare: Connecting research, policy and practice (1st ed., pp. 217-226). Waterloo, ON: Wilfrid Laurier University Press. 
International Journal of Child, Youth and Family Studies (2018) 9(1): 154-167

Office for Standards in Education, Children's Services and Skills. (2014). Looked after children living away from their home area: From a distance. Retrieved from https://www.gov.uk/government/publications/looked-after-children-living-away-from-theirhome-area-from-a-distance

Rogers, J. (2017). 'Different' and 'devalued': Managing the stigma of foster-care with the benefit of peer support. The British Journal of Social Work, 47, 1078-1093. doi:10.1093/bjsw/bcw063

Rutman, D., \& Hubberstey, C. (2016). Is anybody there? Informal supports accessed and sought by youth from foster care. Children and Youth Services Review, 63, 21-27. doi:10.1016/j.childyouth.2016.02.007

Smith, W. (2011). Youth leaving care: A developmental relationship-based approach to practice. New York, NY: Oxford University Press.

Snow, K. (2006). Vulnerable citizens: The oppression of children in care. Journal of Child and Youth Care Work, 21, 94-113. Retrieved from http://www.cyc-net.org/cyconline/cyconline-dec2009-snow.html

Snow, K., \& Mann-Feder, V. (2013). Peer-centered practice: A theoretical framework for intervention with young people in and from care. Child Welfare, 92(4), 75-93.

Snow, K., H., S., \& S., K. (2014). Turning shame into pride: Reshaping stigma by raising voices. The Philanthropist, 25, 119-123. Retrieved from https://thephilanthropist.ca/2013/04/turning-shame-into-pride-reshaping-stigma-by-raisingvoices/

The Children's Society. (2015). Friendship for all: A 'how to' guide to help children in care have more opportunities to make friends. Retrieved from http://www.basw.co.uk/resource/?id=5799

The Children's Society. (2016). Friendship for looked after children Survey Monkey questionnaire report. Retrieved from https://www.childrenssociety.org.uk/sites/default/files/baaf-survey.pdf 